\title{
Value of quinidine in maintenance of sinus rhythm after electric conversion of atrial fibrillation
}

\author{
Gottfried Härtel ${ }^{1}$, Antti Louhija, Aarne Konttinen, and Pentti I. Halonen \\ From the First Department of Medicine, University of Helsinki, Finland
}

\begin{abstract}
One hundred and seventy-five patients with atrial fibrillation treated for the first time with DC shock were divided into two groups according to year of birth. Group I received a long-acting quinidine bisulphate preparation, the dosage of which was adjusted to give serum levels of $I-3 \mathrm{mg} . / \mathrm{l}$. Side-effects were rare with this dosage. Group 2 received no quinidine. Of the 88 patients of group $I$, sinus rhythm was restored in $75(85 \%)$. When leaving the hospital $64(73 \%)$ still had sinus rhythm, and after 3 months $52(59 \%)$. The corresponding figures for the 87 patients of Group 2 were $73(84 \%), 54(62 \%)$, and $30(34 \%)$. The difference at 3 months is statistically highly significant. Because of these results it is concluded that electric conversion of atrial fibrillation should be performed for the first time without quinidine prophylaxis. If there is failure or early recurrence, however, a second electric conversion with subsequent quinidine treatment should be considered.
\end{abstract}

DC shock therapy has become an established method for the restoration of sinus rhythm in atrial fibrillation. The prevention of recurrences of atrial fibrillation after successful conversion remains problematical, however. Controversy exists about the value of antiarrhythmic drugs for this purpose. Quinidine is regarded by many authors as an important drug for the maintenance of sinus rhythm after electric conversion (Lown et al., I963; Hurst et al., 1964; Korsgren et al., 1965; Rossi and Lown, 1967). Dangerous sideeffects have been emphasized by others (Oram and Davies, 1964; Brenner, Davison, and Evans, 1964; Davies, Leak, and Oram, 1965; British Medical Fournal, 1969), and it has been questioned whether quinidine is able to prolong the duration of sinus rhythm at all (Oram and Davies, 1964; Halmos, 1966; Engström, 1967; Hall and Wood, 1968).

The lack of controlled data on the value of prophylactic quinidine prompted the present study.

\section{Subjects and methods}

Our study comprised all the patients of three departments of medicine of the University Central Hospital, Helsinki, who were referred for the first time for electric conversion of their atrial fibrilla-

Received 16 June 1969.

1 Supported by a grant of the Sigrid Juselius Foundation, Helsinki, Finland. tion to the cardiovascular laboratory between May 1967 and June 1968 . During this time cardioversion was attempted for the first time in 207 patients with atrial fibrillation. For various reasons, to be discussed later, 32 patients were discarded from the study, thus leaving 175 patients for final analysis. The patients were divided into two groups: those born in odd years formed the quinidine group, those born in even years formed the control group with no quinidine. Quinidine treatment was started 2 to 5 days before attempted conversion. A long-acting quinidine bisulphate preparation (Kinidin-Duretter @, Hässle) was used and the dosage was adjusted to give serum levels of I-3 mg./l. (Cramér and Isaksson, 1963). This was achieved in most cases with doses ranging from 0.2 to $0.6 \mathrm{~g}$. twice a day, the usual dose being $0.4 \mathrm{~g}$. twice a day. Otherwise the treatment of both groups was the same. Most patients were on digitalis, which was interrupted 36 hours before shock therapy. About one-third of the patients were on anticoagulant therapy. Cardioversion was performed with a synchronized DC defibrillator (Electrodyne) under thiopentone anaesthesia with $0.5 \mathrm{mg}$. atropine sulphate as premedication. A shock of 100 watts was given and, if necessary, additional shocks of 200 and 300 watts. If sinus rhythm was restored, quinidine treatment was continued in the quinidine group. The patients of the control group were left without quinidine. If cardioversion was unsuccessful (primary failures) or if atrial fibrillation recurred during the stay in hospital (secondary failures), the patient was submitted to a cross-over experiment. This means that a second attempt was made as follows: patients of the control group received quinidine 
and those belonging to the quinidine group were given none. If the second trial was successful, quinidine medication was continued in this new quinidine group. The patients were either seen at regular intervals at the out-patient departments or they sent an electrocardiogram after three months with a report on the drugs they had used.

\section{Results}

Of the I75 patients of the present study, 88 were born in odd years and received quinidine and 87 were born in even years and received no quinidine. Details of both groups are given in Tables $I$ and 2.

TABLE I Distribution of patients given quinidine or no prophylactic according to age, sex, and duration of atrial fibrillation

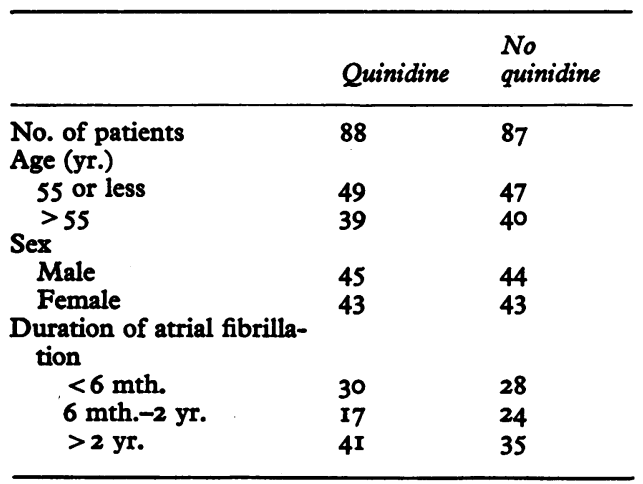

TABLE 2 Aetiology of atrial fibrillation in patients given quinidine or no prophylactic

\begin{tabular}{|c|c|c|}
\hline & Quinidine & $\begin{array}{l}\text { No } \\
\text { quinidine }\end{array}$ \\
\hline $\begin{array}{l}\text { No. of patients } \\
\text { Type of heart disease }\end{array}$ & 88 & 87 \\
\hline Mitral commissurotomy & 29 & 18 \\
\hline $\begin{array}{l}\text { Other rheumatic valve } \\
\text { disease }\end{array}$ & 8 & 12 \\
\hline $\begin{array}{l}\text { Congenital } \\
\text { Coronary }\end{array}$ & $\begin{array}{r}4 \\
20\end{array}$ & $\begin{array}{r}4 \\
22\end{array}$ \\
\hline Myopathic & 6 & 6 \\
\hline Hypertensive & 2 & 2 \\
\hline Thyrotoxic & 6 & 6 \\
\hline Miscellaneous & 2 & 3 \\
\hline 'Lone' atrial fibrillation & I I & 14 \\
\hline
\end{tabular}

In the quinidine group sinus rhythm was restored in 7 patients after starting the usual prophylactic quinidine therapy, making electric conversion unnecessary. Restoration of sinus rhythm occurred in one patient of the control group during digitalization. These patients were not excluded from the respective groups.

Fig. I shows the success rate of conversion in both groups, and the percentages of patients in sinus rhythm when leaving hospital and
Quinidine: 88 patients

No quinidine: 87 patlents

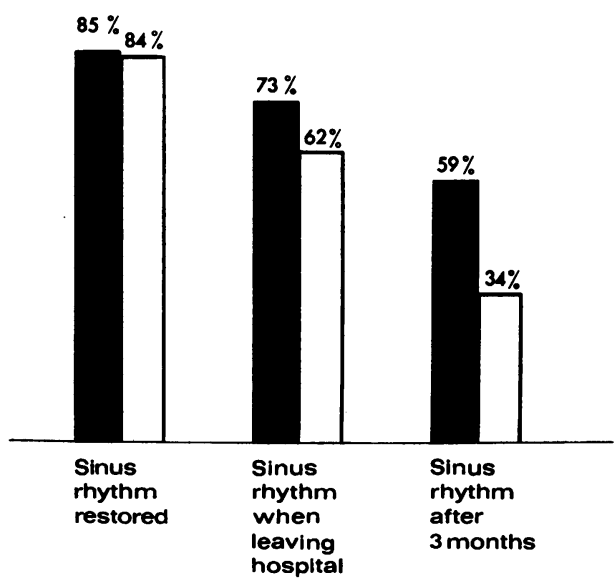

FIG. I Effect of quinidine on the maintenance of restored sinus rhythm.

after three months. The difference in favour of the quinidine group after three months is statistically highly significant $(p<0.00 r)$.

The results of the cross-over experiment of primary and secondary failures are shown in Fig. 2 and 3. It should be pointed out that among the failures in the control group there was one patient in whom sinus rhythm was restored after starting quinidine therapy in prophylactic dosage, and there were two further patients among the secondary failures. All three patients maintained sinus rhythm during the observation period.

FIG. 2 Effect of quinidine on the maintenance of sinus rhythm in cross-over experiment on primary failures. The upper parts of the first columns represent patients in whom no second attempt was made to restore sinus rhythm.

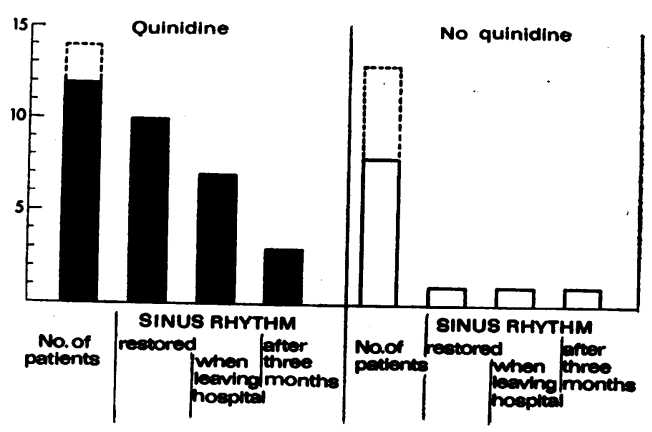




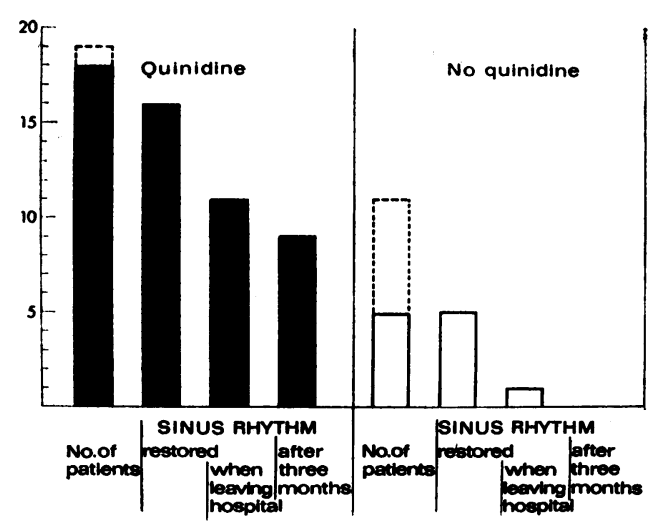

FIG. 3 Effect of quinidine on the maintenance of sinus rhythm in a cross-over experiment on secondary failures. The upper parts of the first columns represent patients in whom no second attempt was made to restore sinus rhythm.

Thirty-two patients were excluded from the final study. The main cause of exclusion (25 cases) was false grouping by the physicians in charge of the patients. Thus, quinidine had been erroneously started in II patients born in an even year, and 14 patients born in an odd year had been given no quinidine. Other causes of exclusion were quinidine intolerance in 4 cases (gastro-intestinal symptoms), and failure to contact the patient after discharge from the hospital in 3 cases. In order to check whether false grouping of the 25 patients might have occurred willingly, thus causing a bias, this group was analysed in regard to age distribution and clinical diagnosis. The patients put wrongly on quinidine did, however, not differ in these respects from those given wrongly no quinidine. As mentioned above, 4 cases developed gastro-intestinal symptoms after starting quinidine therapy. In all other cases quinidine treatment could be continued without side-effects.

One death occurred during the study. The patient was a man aged 70 with effort angina, congestive heart failure, and atrial fibrillation. In spite of a rapid ventricular rate which could not be properly controlled by digitalis, he had ventricular extrasystoles. Restoration of sinus rhythm was considered worth while and this was easily achieved by one shock of roo watts. The ensuing sinus rhythm was slow, however, and digitalis therapy was discontinued two days later because of ventricular extrasystoles occurring as bigeminy. Quinidine therapy was maintained and he continued to have ventricular extrasystoles. One week after cardioversion the patient had a sudden attack of ventricular tachycardia, which was terminated by electric shock. The serum quinidine concentration at this time was $2.2 \mathrm{mg}$./1., and further quinidine was withheld. During the following hours he had atrial fibrillation with multiple ventricular extrasystoles and received procainamide and lignocaine. Later, because of the rapid ventricular rate, he was given digitalis. Hereafter, bouts of ventricular tachycardia appeared which could not be controlled in spite of intensive therapy including multiple electric shocks, drugs such as lignocaine and propranolol, and transvenous artificial pacing. The patient died 19 hours after his first attack of ventricular tachycardia and 30 hours after the last dose of quinidine.

\section{Discussion}

The results of this study show a sinus rhythm maintaining effect of quinidine after restoration of sinus rhythm in patients with atrial fibrillation.

The grouping of the patients according to year of birth resulted in comparability in respect of age, sex, and duration of atrial fibrillation. There were, however, more patients who had been operated on for mitral stenosis in the quinidine group than in the control group (Table I). Analysis of these patients showed that, after commissurotomy, patients on quinidine or without quinidine had the same success rate as the group they belonged to. Thus, the unequal distribution of operated patients did not influence the results.

In spite of the small number of patients, the results of the cross-over experiment are impressive. In this part of the study where every patient was his own control the value of quinidine was evident.

The use of ordinary quinidine sulphate tablets, or lack of control of serum quinidine concentration, or small numbers of patients may explain the negative results obtained by others (Oram and Davies, 1964; Halmos, 1966; Engström, 1967; Hall and Wood, 1968; Radford and Evans, 1968). Fluctuations of the serum quinidine concentration are relatively small with the long-acting quinidine preparation used in this study (Cramér, Varnauskas, and Werkö, 1963), and the twice daily dosage scheme is easy for the patient to carry out.

After exclusion of the 4 patients with primary quinidine intolerance, no side-effects were observed in this study. The role of quinidine in the death of one patient remains unsolved, but seems improbable as the death occurred 30 hours after the last quinidine dose.

We consider the rarity of quinidine sideeffects to be partly due to the fact that a long- 
acting quinidine preparation was used whereby the high peak values obtained with ordinary quinidine sulphate preparations were avoided (Cramér et al., 1963; Cullhed, Hamfelt, and Malers, 1966). Second, a low dosage regimen was used with individual adjustment of the quinidine dose according to serum quinidine values. This is an important point, since, though serum quinidine concentrations in a given patient are fairly constant, there is a remarkable variation in the serum levels obtained in different patients with equal doses (Cramér, 1968).

As is generally known, a considerable number of patients remain in sinus rhythm after DC shock therapy of atrial fibrillation without any antiarrhythmic drugs. This also occurred in the present series. We think, therefore, that the first attempt to restore sinus rhythm should be performed without any antiarrhythmic drug prophylaxis. If there is a failure to restore sinus rhythm or an early recurrence of atrial fibrillation, a second attempt with prophylactic quinidine treatment in low doses and adjusted according to serum quinidine levels, is indicated. Thus, a significant number of additional patients can be maintained in sinus rhythm. However, for each patient it needs to be considered whether the advantages of sinus rhythm outweigh the disadvantages of long-term drug therapy.

\section{References}

Brenner, O., Davison, P. H., and Evans, D. W. (1964). Toxicity of quinidine. Lancet, 2, I 184 .

British Medical fournal (1969). Is quinidine outdated? r, 33r.
Cramér, G. (1968). Early and late results of conversion of atrial fibrillation with quinidine. Acta Medica Scandinavica, Suppl. 490.

- , and Isaksson, B. (1963). Quantitative determination of quinidine in plasma. Scandinavian fournal of Clinical and Laboratory Investigation, 15, 553.

—, Varnauskas, E., and Werkö, L. (1963). A new quinidine preparation with sustained release. Acta Medica Scandinavica, 173, 5 II.

Cullhed, I., Hamfelt, A., and Malers, E. (1966). Serum quinidine concentration with two long-acting quinidine preparations. Acta Medica Scandinavica, 179, 401 .

Davies, P., Leak, D., and Oram, S. (1965). Quinidineinduced syncope. British Medical fournal, 2, 517.

Engström, K. (1967). Kinidinprofylax efter regularisering av förmaksflimmer. Opuscula Medica, 12, 24.

Hall, J. I., and Wood, D. R. (1968). Factors affecting cardioversion of atrial arrhythmias with special reference to quinidine. British Heart fournal, 30, 84.

Halmos, P. B. (1966). Direct current conversion of atrial fibrillation. British Heart fournal, 28, 302.

Hurst, J. W., Paulk, E. A., Proctor, H. D., and Schlant, R. C. (I964). Management of patients with atrial fibrillation. American fournal of Medicine, 37, 728.

Korsgren, M., Leskinen, E., Peterhoff, V., Bradley, E., and Varnauskas, E. (1965). Conversion of atrial arrhythmias with DC shock. Primary results and a follow-up investigation. Acta Medica Scandinavica, Suppl. 431.

Lown, B., Perlroth, M. G., Kaidbey, S., Abe, T., and Harken, D. E. (1963). 'Cardioversion' of atrial fibrillation. A report on the treatment of 65 episodes in 50 patients. New England fournal of Medicine, $269,325$.

Oram, S., and Davies, J. P. H. (1964). Further experience of electrical conversion of atrial fibrillation to sinus rhythm: analysis of 100 patients. Lancet, $\mathbf{I}$, I294.

Radford, M. D., and Evans, D. W. (I968). Long-term results of DC reversion of atrial fibrillation. British Heart fournal, 30, 91.

Rossi, M., and Lown, B. (1967). The use of quinidine in cardioversion. American fournal of Cardiology, 19, 234 . 